\title{
Human Resource Business Partner Mode Transformation Practice in a Chinese State-Owned Company
}

\author{
Liangtie Dai, Jun Qiu \\ Management School of Jinan University, Guangzhou, China \\ Email: srhorse@sina.com
}

Received 11 January 2016; accepted 21 March 2016; published 24 March 2016

Copyright (C) 2016 by authors and Scientific Research Publishing Inc.

This work is licensed under the Creative Commons Attribution International License (CC BY). http://creativecommons.org/licenses/by/4.0/

(c) (i) Open Access

\begin{abstract}
Human Resource Business Partner (HRBP) mode contributes to establishing the closer relationship between HR department and business department, improving efficiency of managing the talents for group enterprises, and also provides the shortcut for HR department's transformation from cost center to profit center. As a state-owned company in China, $\mathrm{X}$ group faces the challenge from both inside and outside old system during HR transformation. Under such circumstances, the HR group spontaneously designs the core training program and mechanism guarantee from top-to-bottom, and helps the traditional HR to become the business partner.
\end{abstract}

\section{Keywords}

Three-Pillar Framework, HRBP Core Ability, HR Transformation Practice, Management Mechanism

\section{Introduction}

Human resource management mode synthesized to generalize and refine the management objectives, processes, content and methods, representing the expression of ideas related to human resource management. Traditionally, functional HR management model consists of six modules which focus on the selection, training and development of the internal employee. However, this mode lacks of effective strategic and business interaction, as well as being difficult to provide tangible value to the actual business. More and more HR departments get subject to cost centers, and being left out in the cold on key issues, while often incurred the voice as "blast Human Resources department" [1] or "it's time to split HR" [2].

On the other hand, as the HR transformation trend picks up, companies begin to drawn the staff from the 
business sector to form the HR team, worsening the traditional HR situation. Such a huge pressure from both inside and outside forced HR practitioners to think about how to change the plight of transition. To achieve this goal, human resource managers need to jump out of the role from developing tools (who emphasized on the innovation of Human resources management tool) to learning from corporate strategy, customer needs, and transferring a functional to a strategic business partner.

Throughout the existing human resources transformation theory, the four-role model proposed by David Ulrich and the three-pillar framework helps to create waves in worldwide HR transformation for their unique qualities of practicality and operability. In China, technology and Internet companies like the Tencent and Huawei already shift to three-pillar system. As for most state-owned enterprises in China, it's seemed to be inevitable to get rid of the constraints derived from the huge bureaucratic system, resulting in weakening the capacity to respond the change from outside market. Thus, it would go a long way toward HR transformation for state-owned enterprises in China. In this paper, we introduce a sample of HR transformation in a state-owned group, particular in the implementation of the three-pillar model and discuss the importance of human resource management model transformation to enhance corporate value.

\section{HR Transformation Difficulty Analysis}

$\mathrm{X}$ group has seized the opportunity by mergers and acquisitions in a few short years to achieve the scale of assets, developing into a platform owned the bank, securities, trust, leasing and other financial license. As it is positioned as a pure financial holding company, the group headquarters of $\mathrm{X}$ group does not directly generate business profits, but adds the value via establishing the multifaceted control system, and creates the synergies between the various business units. After the start-up, $\mathrm{X}$ group now is moving into the rapid development of the "fast track", putting forward the new demand for the headquarters to upgrade the level of specialization control.

Human capital management has become one of the key success factors to measure the competitiveness for financial enterprises, and often easily overlooked by growing enterprise. Till now, $\mathrm{X}$ group hires more than 5000 staff, while the HR services ratio is about 1:90, and the HRM base construction is relatively weak. In a summary, overall organizational diagnosis reveals that the presence of Group HR lies in two core issues.

\subsection{Invisible Wall}

Initially, HR post-setting in the headquarters aims at meeting the basic daily personnel management, gradually reveals some problems: Firstly, the single teaching means of HR control towards the subordinate enterprises only limits to assessing the executives of the subsidiary and designing motivation methods; Secondly, HR group in the headquarters office soaked in a comfortable position of the circle in year out, seldom did they go for docking subsidiary business opportunities, and gradually there shaped an invisible wall between HR department and business unit.

\subsection{HR Competency Defect}

A group of key executives in the subsidiary business unit are most business background. Most of them focus the on business development, whereas easily neglect of the talent management and system construction. Specifically, new business often lagged behind the competitor mainly due to the lack of personnel training and brain drain. HR in subsidiaries still shows uneven development status: besides the core company owns relatively large-scale HR department, other's HR function has not been out of the administrative department control.

In addition, each subsidiary company's human resources still stayed the exercise of the duties of the personnel management process, obtaining limited resources and support from headquarters. And for HR practitioners, the biggest challenge lies in the lack of willingness and confidence in leading the business.

\section{Preparations for HRBP Mode Transformation}

There is no doubt that business drives the management restructuring. Successful HR transformation involves upgrading the entire operating model and accountability mechanisms, and contributes to a top-down driven project. Before the implementation of the transition, $\mathrm{X}$ group make the following preparations: 


\subsection{Clear Target for HR Strategic Transformation}

Before implementing the transition plan, designers must clearly set the appropriate vision, and make sure this work could provide a real performance boost.

HR transformation plays a central value in two ways for $\mathrm{X}$ group: First, transformation could support the role of corporate strategy for landing by playing the role of middleman to assist strategic landing in the front line; the second way is to promoting the role to level up the group's operations and services of system. That is to say, starting from HR lines, headquarters could provide professional guidance and resource sharing for all group members.

\subsection{Design the New Organizational Structure and Optimization}

In the three-pillar model of human resources, the HR role is liberated from the modular functions of fixed role, forming three new customer-oriented services, new structure include three parts: Expert Center COE (Center of Expertise), business partner BP (Business Partner,) and shared services centers SSC (Shared Service Centre).

HR Business Partner locates in the front process, combining with the dual advantage of business and HR knowledge. HRBP member needs to possess the skills to identify and solve the problems in the business sector, delivers the tough ones to a specialist center team.

Center of Expertise consist of experts in various HR fields, being responsible for the design of control framework, and presided over special programs and research.

Shared Services Center plays the role of backup support, carry on the most function work, in order to reduce the pressure of the other role.

Under the three-pillar structure, traditional HR shift to business service center through internal tripartite formation of three parts with a clear division of responsibilities and process integration.

Based on the "division” type of HRBP mode, X group build a HRBP team including the affiliated companies colleagues, and divides them into three kinds of HRBP according and the similarity of business: HR Banking BP (including banking, leasing etc.), securities industry BP (including securities, trusts, funds, etc.) as well as small and micro finance BP group (see Figure 1).

Under the three-pillar structure, traditional HR shift to business service center through internal tripartite formation of three parts with a clear division of responsibilities and process integration.

Obliviously, it's impossible to push the three-pillar structure landing in a short term. Generally, when faced with the transformation, most enterprises choose to start with the SSC building and invest money for setting up the E-HR system and personnel outsourcing [3]. Given the current organizational ability status and business de-

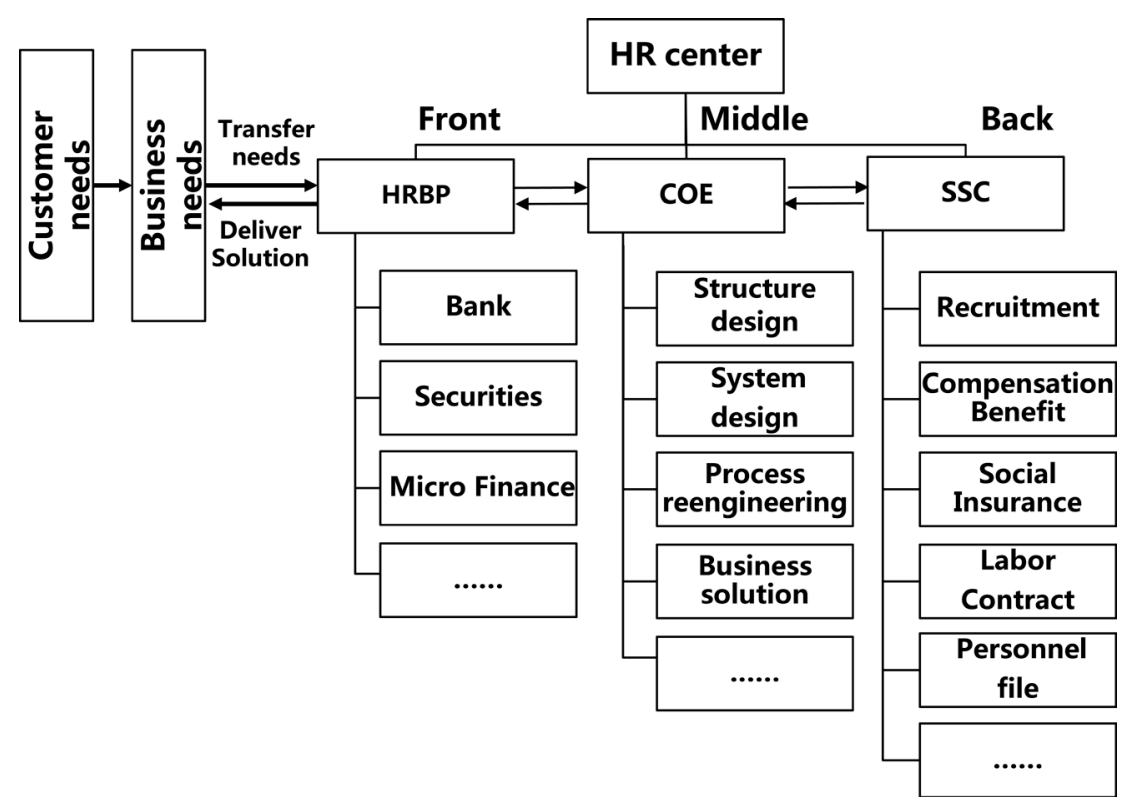

Figure 1. HR center organization structure in X group. 
velopment demanding, X Group focus on making the connection between HR practitioner and business unit at the beginning of the transition.

\subsection{HRBP Role Analysis and Ability Diagnoses}

From the structure mentioned above, HRBP located in the front of the whole HR system, contributing to the functioning of the entire HR system. Meanwhile, the output of HRBP directly affects the overall quality of service. To become a professional in leading business development, HRBP need to master knowledge of human resources and related management practices, getting closer to business and achieve mutual integration of multiple roles.

Professor Dave Ulrich proposed initial framework HRBP in "HR champion" in 1996, this role includes strategic partners Change Agent, Employee Champion, and Functional Expert. Then, in the "HR value proposition" his former role models were revised into five more specific roles [4], he adds the role of Leader and Human Capital Developer, integrates the change agents into the strategic partners, forming a five-character model (see Figure 2).

The connotation of HR's strategic role has extended in the five model. Compared to other roles, HRBP is more likely to be a strategic partner to undertake organizational strategy for mission, relying on the ability to build a strong organization to ensure the strategic landing. This requires organizational development HRBP to rapidly diagnose pain points, thereby pulling organize projects, processes, and culture change.

Guided by the five-role model, the HR team extracts the appropriate quality, then undergoes the ability diagnose to assess the current situation, and on this basis identify potential gaps. The results show that the HR team in the $\mathrm{X}$ group are still largely conditioned by functional system, and there exists the significant competency gaps compared with HRBP, mainly in the following areas:

- The absence of strategic and business acuity, lack of customer-oriented awareness;

- Insufficient professional knowledge in change management, poor data analysis ability;

- Low level of confidence and initiative when facing the business challenges.

\section{Ability Improvement Plan}

To achieve the transition to HRBP, the first task for functional HR is to develop strategic business knowledge and strengthen the ability to boot the change [5]. Combining with the HRBP job responsibilities, the HR transition team carry out a three-stage training to close the ability-gap. This program will follow " 721 " rule ${ }^{1}$, and place emphasis on the on-job practice. The course content in the first two phases promotes the business knowledge and methods, while add the post practice and action learning in the third stage to ensure the consistency between knowledge, learning, and the organizational development. Under this program, HR practitioner could make up for challenging experiences through both team training and personal development which focus on current businesses challenges. In addition, this training program ties the HRBP qualification to individual promotion by adding the corresponding impact assessment and refresher mechanisms, which ensure that each HRBP can with stand the test from business sector (see Figure 3).

The first phase of this study focus on "Business knowledge and benchmarking enterprise value model innovation learning”. The instructor must have an accurate grasp and profound insights into the external business envi-

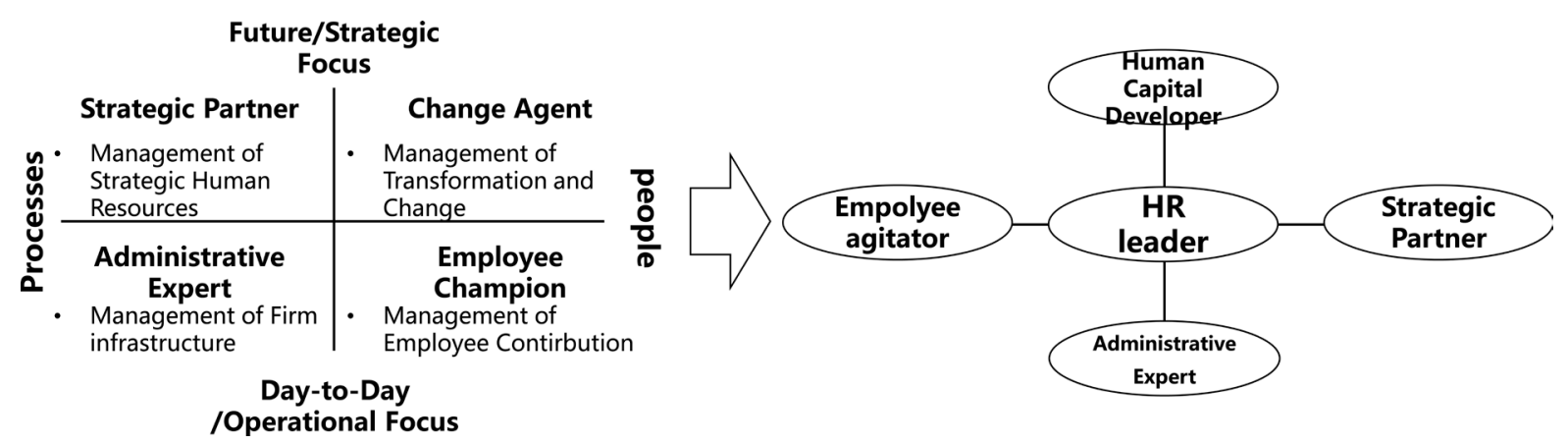

Figure 2. HR role model transformation.

${ }^{1}$ The effect of training derives from courses and reading for $10 \%$, learning form others for $20 \%$, and on-job practice for $70 \%$. 

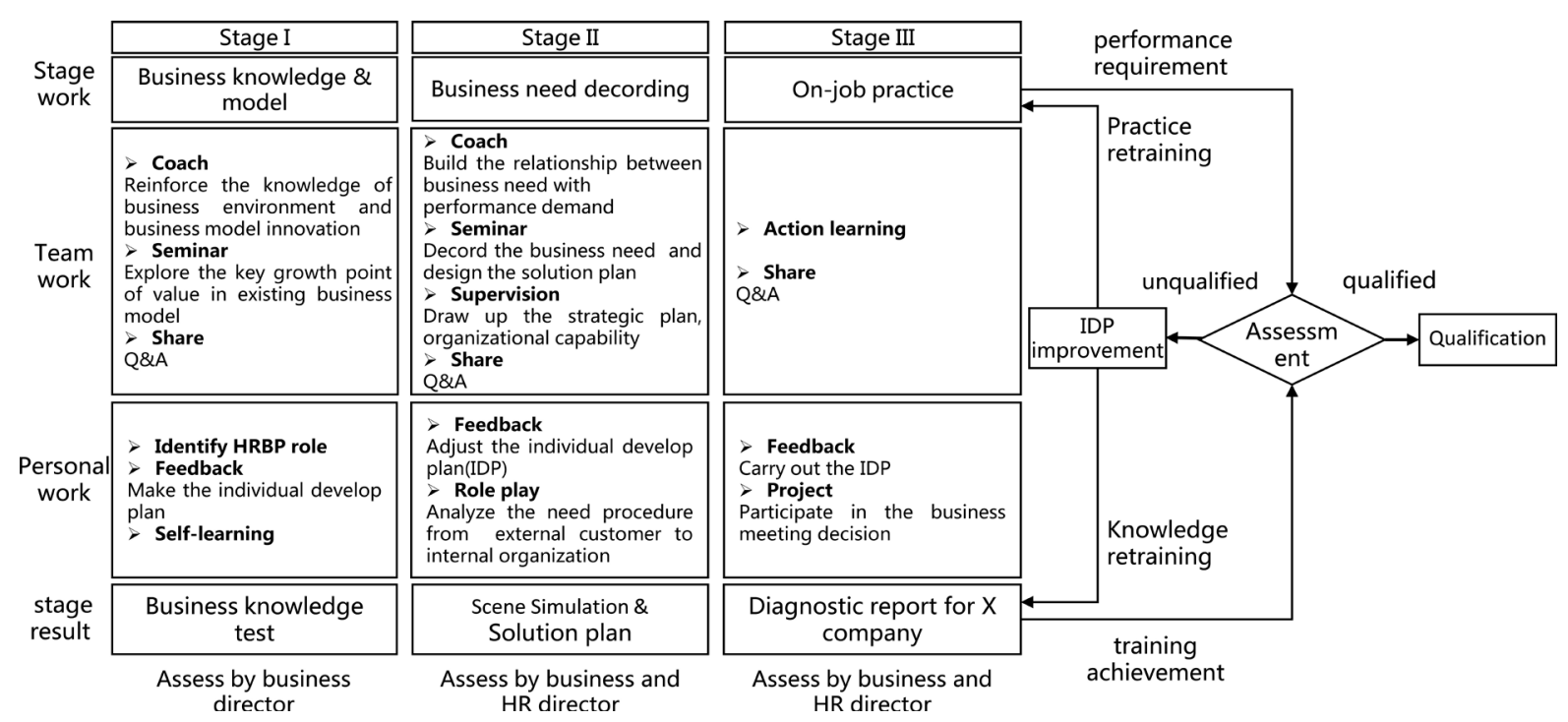

Figure 3. HRBP training program plan.

ronment, usually served directly from the subsidiary business line. Courses start from the macro financial development, and then explain the current business development situation. The core goal is to help HR get rid of fuzzy perception of business, instead, they are required to understand the language of business progress. Second goal is to develop business awareness, researchers has found that business awareness competencies are important differentiators between strategic and functional HR roles [6], and tap the new value from existing business model, seeking the potential to trigger changes. This process requires HR team not only learn the best practices of external benchmarking companies, but also integrate the internal resources to design the optimal, risk-controlled portfolio model from the group view.

Compared with the first phase of the "soft power shape", the second phase emphasis on methods and strategies from the perspective of human resources. The course put "customer-business units-organizational development" as the main line, and explore the operational and performance demands behind the customer need [7]. HR team need to learn the tool of capability diagnosis, talent review and other means to develop and align human resources strategy planning.

After accumulation of knowledge and skills, HR team are requested to solve real business problems in practice, and make up challenging experience at the same time. Starting with a relatively weak sector, all team members are divided into small groups to complete the overall diagnostic business lines from the strategic to the mechanism. What's more, the group held regular seminars to encourage various communication across departmental boundaries, to achieve cooperation linkage and enhance synergies between different lines.

The HRBP team use the business affiliated securities companies as an entry point for practice case, for example, recently the market showed a steady upward trend and a huge space for future development, but are trapped into the problem like the shortage of cash and talent flow, the lack of mechanisms for cooperation and so on. For this situation, HR team responded quickly to increase the urgency of the action plan, combing to the analyze of the main value chain and operating status, then try to find the breakthrough point to grab business pain points: Firstly, the team explore the opportunities to introduce other investment sectors / companies in the capital side, actively participate in decision-making meetings, and help promote the project schedule; on the other side of talent management, HR team concentrates on optimizing business behavior patterns by review the talent ability, and focus on incentives to retain the core team; On the basis of the former two points, they are seeking to introduce the investment research departments and agencies to provide research support for business department, as well as improve the product design capabilities.

HRBP team actively assist the subordinates company to complete the revision and design systems to ensure human resources strategy landing effectively. Furthermore, HR team acts in a consulting role through integration of resources, to some extent, promotes the development of this section of the core business. In a result, the project has eased the sharp contradictions from funds, sectoral interests and personnel incentives, and successfully lay the foundation for rapid development. 


\section{Management Mechanism for the Growth of HRBP}

\subsection{Performance Management}

HRBP role has multiple compound, with its output and businesses linking directly to the performance. Thus, traditional methods that sometimes cannot adapt to the development of position. Generally, the role of HRBP is used to be divided into divisional BP and representatives of type BP: the divisional BPs are located in the business sector, only to accept the professional recommendations by headquarters; while the representative were still full integrated overall management [8].

Since the HR scale and capacity in $\mathrm{X}$ group is still forming, the development of management direction of HRBP are becoming more and more matrixed and vertical. Under the bi-directional management, the annual promotion assessment and employee development of BP team were grasped by the headquarters, and affiliated companies are responsible for compensation, performance management, and staff relations. Secondly, as most BPs are not born out of the traditional functions of type HR, they also need transitional period to take a certain amount of daily affairs. Thus, this forced the performance indicator system to transfer from a one-dimensional (former job description) to multidimensional (project). In particular, the effect of project delivery and organizational talent development are in additional to the original basis of job requirements, focusing on quantitative indicators of assessment, such as the key to improving the rate of job losses, indicators of human capital ROI. At last, the business executives (internal customers) and external customers are brought into the evaluators to strengthen customer service awareness of HRBP.

\subsection{Career Development}

In the process of transition from traditional role to BP, the HR practitioner faces many challenges and risks, being inclined to the extreme when deal with their role-marginalized by business or assimilation. In order to learn more about the business, BP should take the initiative to break the "functional-Business wall". And assimilation means that BP bear huge occupational risks from the pressure of business knowledge learning and way to change the original work pattern. Assimilation would lead the HR to become the vassal of business department, then evolves into a vicious career development bottleneck, and degenerates into a "buddy". To resolve this problem requires not only BP himself reflect on their own ability, but also cannot do without system support.

$\mathrm{X}$ group has congenital advantage in its multi-sector resources to offer HRBP a wide and clear career map. Considering that, the headquarters plan to build a flexible mechanism for the flow of talent from the horizontal/vertical directions, guiding professional risk spread to the outside. The overall pattern shows in the form of three paths (See Figure 4). BP's own development path passes through the transactional, tactical and strategic in

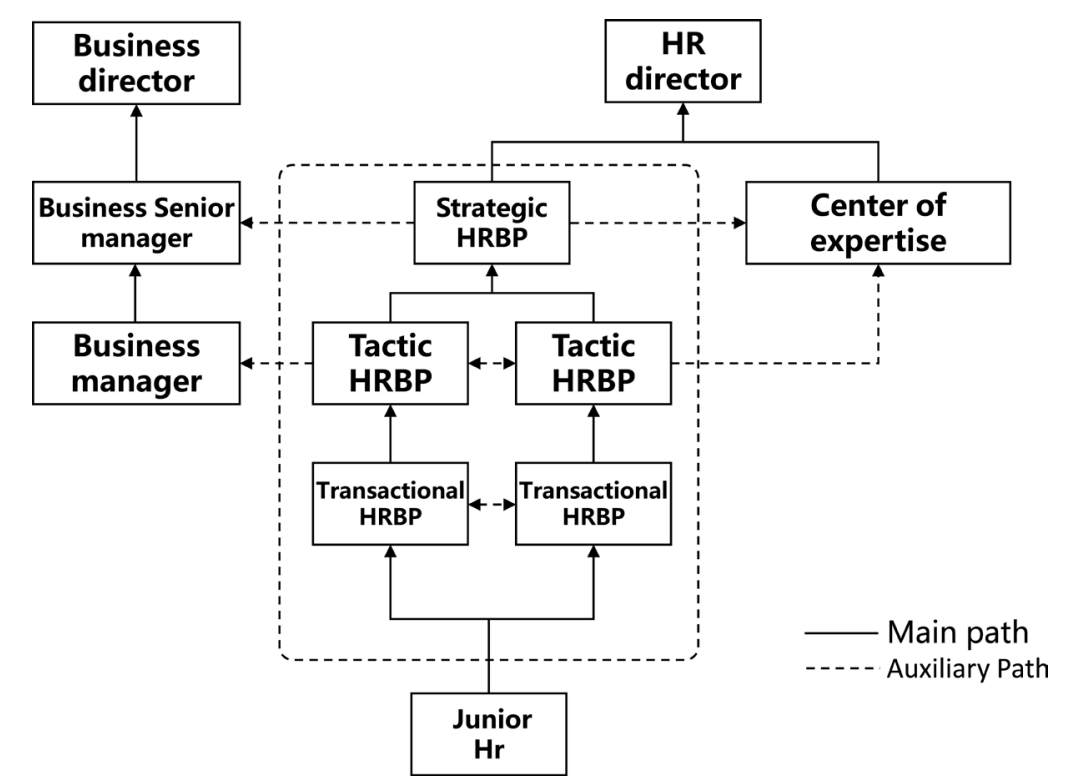

Figure 4. The inside and outside development path for HRBP. 
the longitudinal dimension. Senior BP spend a lot of time to design HR strategy, BP team management and communication and collaboration with the other two centers to strategic; and primary BP are more involved in HR strategy implementation. From the lateral view, HPBP can be rotation between business groups to increase business acumen in different fields, also could be transfer to the COE HR within the HR center. Some restrictions to the business part also are suggested to be loosen if the senior BP get relative qualification to do real business, it's another way to realize the post matching [9].

\section{References}

[1] Stewart, T.A. and Woods, W. (1996) Taking on the Last Bureaucracy. Fortune-European Edition, 133, 67-70.

[2] Charan, R. (2014) It’s Time to Split HR. Harvard Business Review, 92, 33-34.

[3] McCracken, M. and McIvor, R. (2013) Transforming the HR Function through Outsourced Shared Services: Insights from the Public Sector. The International Journal of Human Resource Management, 24, 1685-1707. http://dx.doi.org/10.1080/09585192.2012.725070

[4] Ulrich, D. and Brockbank, W. (2005) The HR Value Proposition. Harvard Business Press, 301-331.

[5] Lo, K., Macky, K. and Pio, E. (2015) The HR Competency Requirements for Strategic and Functional HR Practitioners. The International Journal of Human Resource Management, 1-21. http://dx.doi.org/10.1080/09585192.2015.1021827

[6] Gollan, P.J. (2012) HR on the Line: Human Resource Managers' Contribution to Organisational Value and Workplace Performance. Asia Pacific Journal of Human Resources, 50, 288-307. http://dx.doi.org/10.1111/j.1744-7941.2012.00025.x

[7] Robinson, D.G. and Robinson, J. (2005) Strategic Business Partner: Aligning People Strategies with Business Goals. Berrett-Koehler Publishers, 16-17.

[8] Cong, L., Wang, J., Business, S.O. and University, N. (2013) The Four Typical Pattern of Human Resource Business Partner. Human Resources Development of China.

[9] Guan, Y., Yang, W., Zhou, X., Tian, Z. and Eves, A. (2016) Predicting Chinese Human Resource Managers’ Strategic Competence: Roles of Identity, Career Variety, Organizational Support and Career Adaptability. Journal of Vocational Behavior, 92, 116-124. http://dx.doi.org/10.1016/j.jvb.2015.11.012 